Article

\title{
Phytogenotypic Anthocyanin Profiles and Antioxidant Activity Variation in Fruit Samples of the American Cranberry (Vaccinium macrocarpon Aiton)
}

\author{
Rima Urbstaite ${ }^{1, *}$, Lina Raudone ${ }^{1,2}$ (D) and Valdimaras Janulis ${ }^{1}$ (D) \\ 1 Department of Pharmacognosy, Faculty of Pharmacy, Lithuanian University of Health Sciences, \\ 50166 Kaunas, Lithuania; lina.raudone@lsmuni.lt (L.R.); valdimaras.janulis@lsmuni.lt (V.J.) \\ 2 Laboratory of Biopharmaceutical Research, Institute of Pharmaceutical Technologies, \\ Lithuanian University of Health Sciences, 50166 Kaunas, Lithuania \\ * Correspondence: rima.urbstaite@lsmu.lt; Tel.: +370-696-779-17
}

\section{check for}

updates

Citation: Urbstaite, R.; Raudone, L.; Janulis, V. Phytogenotypic

Anthocyanin Profiles and Antioxidant Activity Variation in Fruit Samples of the American Cranberry (Vaccinium macrocarpon Aiton). Antioxidants 2022, 11, 250. https://doi.org/10.3390/ antiox 11020250

Academic Editors: Agustín G. Asuero and Noelia Tena

Received: 27 December 2021

Accepted: 25 January 2022

Published: 27 January 2022

Publisher's Note: MDPI stays neutral with regard to jurisdictional claims in published maps and institutional affiliations.

Copyright: () 2022 by the authors Licensee MDPI, Basel, Switzerland. This article is an open access article distributed under the terms and conditions of the Creative Commons Attribution (CC BY) license (https:// creativecommons.org/licenses/by/ $4.0 /)$.

\begin{abstract}
In this study, we conducted an analysis of the qualitative and quantitative composition of anthocyanins and anthocyanidins in different cultivars and genetic clones of American cranberries grown in Lithuanian climatic conditions. Four anthocyanin compounds predominated in fruit samples of American cranberry cultivars: cyanidin-3-galactoside, cyanidin-3-arabinoside, peonidin-3galactoside, and peonidin-3-arabinoside. They accounted for $91.66 \pm 2.79 \%$ of the total amount of the identified anthocyanins. The total anthocyanin content detected via the $\mathrm{pH}$ differential method was found to be by about 1.6 times lower than that detected via the UPLC method. Hierarchical cluster analysis and principal component analysis showed that the 'Woolman' cultivar distinguished from other cranberry cultivars in that its samples contained two times the average total amount of anthocyanins $(8.13 \pm 0.09 \mathrm{mg} / \mathrm{g})$. The group of American cranberry cultivars 'Howes', 'Le Munyon', and 'BL-8' was found to have higher than average levels of anthocyanidin galactosides (means $3.536 \pm 0.05 \mathrm{mg} / \mathrm{g}$ ), anthocyanidins (means $0.319 \pm 0.01 \mathrm{mg} / \mathrm{g}$ ), and total anthocyanins (means $6.549 \pm 0.09 \mathrm{mg} / \mathrm{g}$ ). The evaluation of the antioxidant effect of cranberry fruit sample extracts showed that the greatest radical scavenging activity of the cranberry fruit extracts was determined in the fruit samples of 'Woolman' (849.75 $\pm 10.88 \mu \mathrm{mol} \mathrm{TE} / \mathrm{g})$ and the greatest reducing activity was determined in 'Le Munyon' (528.05 $\pm 12.16 \mu \mathrm{mol} \mathrm{TE} / \mathrm{g})$. The study showed a correlation between the total anthocyanin content and the antiradical and reductive activity of the extracts in vitro (respectively, $\mathrm{R}=0.635$ and $\mathrm{R}=0.507, p<0.05$ ).
\end{abstract}

Keywords: cranberry; anthocyanidin; antioxidant activity; UPLC; Vaccinium macrocarpon

\section{Introduction}

The American cranberry (Vaccinium macrocarpon Aiton) is a perennial evergreen plant of the Ericaceae A.L. de Jussie family growing in natural habitats in North America [1-3]. The selection of cranberry cultivars began in the U.S. in the early 1800s, in studies with cranberry plants growing in natural cenopopulations [4]. More than 200 cultivars of American cranberries are cultivated worldwide [5]. According to the data for 2019, the United States, Canada, and Chile provide $98 \%$ of world cranberry production [6].

In the climatic conditions of Lithuania, small cranberries (Vaccinium oxycoccos L.) grow in the natural cenopopulations of raised bogs and intermediate-type wetlands [7]. During the land reclamation works in Lithuania, those raised bogs and intermediate-type wetlands were drained, which decreased the areas of small cranberry habitats [7]. In about 1967, the selection and introduction of the first cultivars of American cranberries as a perennial berry culture began in Lithuania [8]. Recently, the cultivation of the introduced cranberry cultivars in Lithuania has gained popularity [7]. 
The most important groups of biologically active compounds found in cranberry fruits are flavonols (derivatives of quercetin and myricetin) [9], flavan-3-ols, anthocyanins [10], phenolic acids [11], and triterpenoids [12]. The cranberry-specific proantocyanidin and flavonol complex possess antiadhesive activity to the uropatogenic strains of Escherichia coli [13]. The effects of these biologically active compounds in cranberry fruit determine the use of the fruit in the prevention and treatment of urinary tract infections [14]. Studies on the effects of cranberry fruit extracts showed that quercetin in those extracts inhibited cell proliferation and reduced the growth of bladder [15] and ovarian [16] cancer cells [17].

Anthocyanins and anthocyanidins are one of the most important groups of biologically active compounds in cranberry fruit. Pappas and Schaich have found that in samples of freshly harvested cranberries, their levels could vary from 13.6 to $171 \mathrm{mg} / 100 \mathrm{~g}$ [18]. About $90 \%$ of the total amount of anthocyanins in cranberry samples are cyanidin and peonidin glycosides (cyanidin-3-arabinoside, cyanidin-3-galactoside, peonidine-3-arabinoside, and peonidine-3-galactoside) [19]. The other components of the anthocyanin complex in cranberry fruit make up a small percentage, amounting to about $10 \%$. Of these, glycosides of delphinidin, cyanidin, petunidin, and malvidin are worth mentioning, as their molecules contain various monosaccharides [19].

Yan et al. found that cyanidin-3-galactoside isolated from cranberry fruit extract was capable of scavenging free radicals and inhibiting the oxidation of low-density lipoproteins [20]. Ho et al. performed studies in mice and found that peonidin-3-glucoside reduced the number of the metastases of lung carcinoma cells [21]. Smeriglio et al. found a glycemia-lowering effect of cyanidin-3-glucoside [22].

Seeram et al. found that the anthocyanin fraction in cranberry fruit extracts inhibited inflammatory processes [23], and cranberry fruit extract reduced inflammatory processes in the liver [24]. Santana et al. conducted studies in mice and found that cranberry fruit extract was effective in the treatment of acute pancreatitis [25]. Seeram et al. conducted studies with cancer cell lines. The studies showed that anthocyanins, proanthocyanidins, and flavonol glycosides isolated from cranberry fruit extracts had antiproliferative effects on oral, colon, and prostate cancer cells [26].

Cranberry fruits, both fresh and processed, are used in the production of food supplements, juice, and in the confectionery industry [7,8]. Cranberry fruits and their extracts could be used as natural preservatives, since the biologically active compounds (anthocyanins and phenolic compounds) found in them have antioxidant and antimicrobial effects. Phenolic compounds have antimicrobial activity against bacterial and fungal strains that can cause food spoilage and poisoning [27]. Anthocyanins obtained from cranberry fruit are used as food colorants in confectionery [28]. The ability of anthocyanins to change color from red to blue and other shades depending on the $\mathrm{pH}$ of the environment can be used to determine the quality and shelf life of perishable foods and to create smart food packaging $[29,30]$. The biologically active compounds of cranberry fruit-anthocyanins-can have antimicrobial, antioxidant, and other effects on disease prevention and health in the development of healthy and ecological food products.

The studies of the qualitative and quantitative composition of anthocyanins in cranberry samples are important for the evaluation of the quality of food products, food supplements, and pharmaceuticals. The preparation of high commercial value raw material of cranberry fruit should be based on the evaluation of phytochemical profiles, especially anthocyanins and their distribution in cultivated or wild cranberries.

Determination of anthocyanins content in cranberry fruit are important for the evaluation of fruit samples of small cranberries (Vaccinium oxycoccos) and American cranberries (Vaccinium macrocarpon) and their cultivars, determining the regularities of the accumulation of biologically active compounds, the optimal time of berry harvesting, and the selection of the most promising cranberry cultivars for introduction.

This study aimed to determine the anthocyanin profiles and antioxidant activity of the fruits of Vaccinium macrocarpon cultivars. The performed research will provide new knowledge about the variation in the qualitative and quantitative composition of 
anthocyanins in cranberry cultivars and is important in determining the most promising cranberry cultivars for cultivation in Lithuanian climatic conditions.

\section{Materials and Methods}

\subsection{Reagents}

Acetonitrile (manufacturer: Sigma-Aldrich, Steinheim, Germany), methanol (manufacturer: Sigma-Aldrich, Steinheim, Germany), formic acid (manufacturer: Merck, Darmstadt, Germany), reference standards for delphinidin-3-galactoside, cyaniding-3-galactoside, cyaniding-3-glucoside, cyaniding-3-arabinoside, peonidin-3-galactoside, peonidin-3-arabin oside, peonidin-3-glucoside, malvidin-3-galactoside, malvidin-3-arabinoside, cyanidin chloride, peonidin chloride, and malvidin chloride were purchased from Extrasynthese (Genay, France). ABTS 2,2'-Azino-bis(3-ethylbenzothiazoline-6-sulfonic acid), Trolox (6-hydroxy2,5,7,8-tetramethylchroman-2-carboxylic acid), potassium peroxydisulfate, sodium acetate (manufacturer: Scharlau Sentmenat, Barcelona, Spain), ferric (III) chloride hexahydrate (manufacturer: Vaseline-Fabrik Rhenania, Bonn, Germany), TPTZ (2,4,6-Tris(2-pyridyl)-striazine) (manufacturer: Carl Roth, (Karlsruhe, Germany), acetic acid (manufacturer: Lach Ner, Neratovice, Czech Republic), hydrochloric acid (manufacturer Sigma-Aldrich, Steinheim, Germany), potassium chloride, and ethanol 96\% $(v / v)$ (manufacturer: AB Stumbras, Kaunas, Lithuania) were also acquired.

\subsection{Raw Material}

The fruits examined in the present study were mature and ripe fruit of different cultivars of American cranberry (Vaccinium macrocarpon Aiton) (Table 1) grown in Lithuanian climatic conditions, in the collection of the Institute of Botany of the Nature Research Center, Mažieji Gulbinai, Vilnius ( $\left.54^{\circ} 41^{\prime} 36.6^{\prime \prime} \mathrm{N} 25^{\circ} 21^{\prime} 56.0^{\prime \prime} \mathrm{E}\right)$. Dynamics of meteorological factors (precipitation $(\mathrm{mm})$, sunshine duration $(\mathrm{h})$, and temperature $\left({ }^{\circ} \mathrm{C}\right)$ ) in region of Vilnius in 2020 are presented in Figure 1 [31]. The collection time was September 2020. Cranberry fruits were ground and frozen at $-60{ }^{\circ} \mathrm{C}$ in an ultra-low-temperature freezer $(\mathrm{CVF} 330 / 86$, ClimasLab SL, Barcelona, Spain). Cranberry fruits were freeze-dried according to the methodology described by Gudžinskaitè et al. [32]. The fruits were powdered in a Retsch GM 200 electric mill (Retsh GmbH, Hahn, Germany). Loss on drying was determined using the method described in the European Pharmacopoeia Ph.Eur.01/2008: 20232 [33].
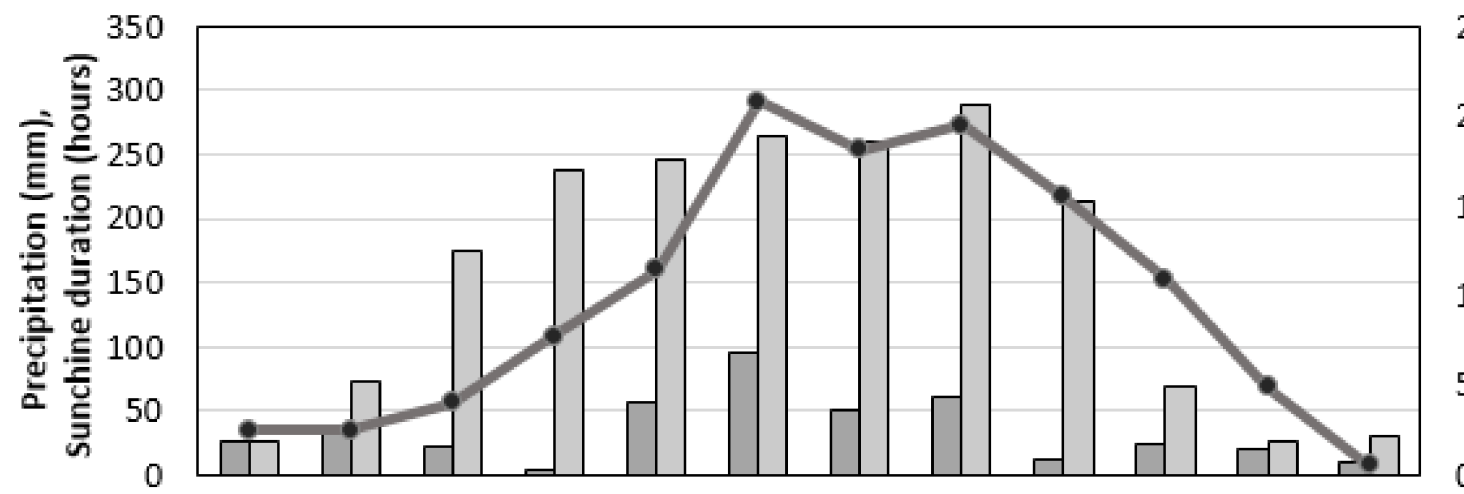

25

20

总

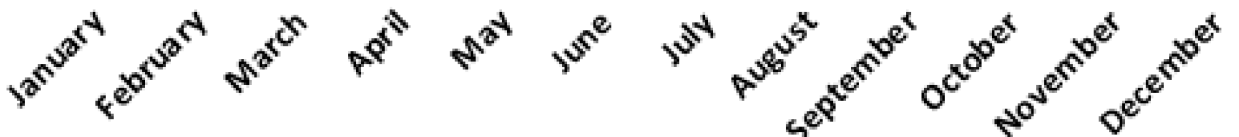

15

10

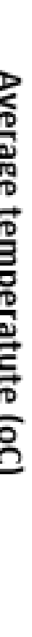

Precipitation

Sunshine duration

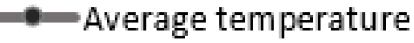

Figure 1. General climate condition (temperature, precipitation, and sunshine duration) in region of Vilnius in 2020. 
Table 1. Characteristics typical of American cranberry cultivars; ND (no data).

\begin{tabular}{|c|c|c|c|c|}
\hline No. & Cranberry Cultivar & $\begin{array}{l}\text { Country of } \\
\text { Origin and Year }\end{array}$ & Cultivar Characteristics & Reference \\
\hline 1 & 'Baifay’ & ND & ND & \\
\hline 2 & 'Bergman' & 1961 & $\begin{array}{l}\text { 'Early Black' × 'Searles' hybrid, abundantly growing, } \\
\text { medium-early, fertile. The berries are suitable for storage. }\end{array}$ & {$[4,8]$} \\
\hline 3 & 'Crowley' & 1961 & $\begin{array}{c}\text { 'McFarlin' } \times \text { 'Prolific' hybrid. The berries are of medium size, } \\
\text { dark red, suitable for processing. }\end{array}$ & {$[4,8]$} \\
\hline 4 & 'Early Black' & 1835, MA, USA & $\begin{array}{l}\text { Native Selection. The berries are of medium size, sometimes small, } \\
\text { blackish red. It grows abundantly and is moderately fertile. }\end{array}$ & {$[4,8,34]$} \\
\hline 5 & 'Early Richard' & $1870, \mathrm{NJ}, \mathrm{USA}$ & $\begin{array}{l}\text { A medium early cultivar. Medium-sized, dark red berries. Grows } \\
\text { abundantly. The berries are not very suitable for storage. }\end{array}$ & {$[8,35]$} \\
\hline 6 & 'Habelman' & ND & ND & \\
\hline 7 & 'Holliston' & 1885, MA, USA & Native Selection, a medium-early cultivar. & [36] \\
\hline 8 & 'Howes' & 1843, MA, USA & $\begin{array}{l}\text { Native Selection. A late cultivar, disease resistant, fertile. The } \\
\text { berries are small, medium-sized, store a lot of pectin, are suitable } \\
\text { for storage, and are resistant to frost. }\end{array}$ & {$[4,8,34]$} \\
\hline 9 & 'Le Munyon' & $1960, \mathrm{NJ}, \mathrm{USA}$ & $\begin{array}{l}\text { Native Selection, a very early fertile cultivar with medium-sized } \\
\text { large dark red berries. }\end{array}$ & {$[4,8,34]$} \\
\hline 10 & 'McFarlin' & 1874, MA, USA & Native Selection. & {$[4,34]$} \\
\hline 11 & 'Prolific' & 1900, MI, USA & Native Selection. & {$[4,34]$} \\
\hline 12 & 'Searles' & 1893, WI, USA & $\begin{array}{l}\text { Native Selection. A medium-early cultivar. The berries are large, } \\
\text { red, not suitable for storage. The cultivar is fertile, with high } \\
\text { matching stems. }\end{array}$ & {$[4,8,34]$} \\
\hline 13 & ‘Woolman' & 1897, NJ, USA & An early cultivar. & {$[8,35]$} \\
\hline 14 & 'Ar-2' & ND & A late cultivar. & [8] \\
\hline 15 & 'Bain-6’ & WI, USA & Native Selection. & [36] \\
\hline 16 & 'Bain-MC' & ND & A late cultivar. & [8] \\
\hline 17 & 'BL-8’' & ND & $\begin{array}{l}\text { Is characterized by early berry ripening, lush growth, and } \\
\text { medium-sized, large, dark red, oval berries. }\end{array}$ & [8] \\
\hline 18 & 'BL-12' & ND & ND & \\
\hline 19 & 'BL-15’ & ND & $\begin{array}{l}\text { Is characterized by early berry ripening, lush growth, and } \\
\text { medium-sized, large, dark red, oval berries. }\end{array}$ & [8] \\
\hline 20 & ‘BL-22’ & ND & ND & \\
\hline
\end{tabular}

\subsection{Preparation of Cranberry Extracts}

About $1 \mathrm{~g}$ (precise weight) of the lyophilized cranberry powder was extracted with $20 \mathrm{~mL}$ of $70 \%(v / v)$ ethanol containing 1\% hydrochloric acid in an ultrasonic bath for $15 \mathrm{~min}$ at $80 \mathrm{kHz}$ and $565 \mathrm{~W}$ at room temperature. The extract was collected and filtered through a membrane filter with a pore size of $0.20 \mu \mathrm{m}$. The prepared extracts were stored in dark glass vials at $-20^{\circ} \mathrm{C}$.

\subsection{Spectrophotometric Studies}

\subsubsection{Determination of Antioxidant Activity}

An ABTS + radical cation decolorization assay was applied according to the methodology described by Re et al., 1999 [37] and modified by Raudone et al. [38]. A volume of $3 \mathrm{~mL}$ of $\mathrm{ABTS}^{+}$solution (absorbance $0.800 \pm 0.02$ ) was mixed with $5 \mu \mathrm{L}$ of the 5 -fold diluted cranberry extract. A decrease in absorbance was measured at a wavelength of $734 \mathrm{~nm}$ after keeping the samples for $30 \mathrm{~min}$ in the dark. A standard curve $(y=0.000008 x-$ 
$\left.0.0909 ; \mathrm{R}^{2}=0.997\right)$ was produced by using standard Trolox solutions of $4000-48,000 \mu \mathrm{mol} / \mathrm{L}$ concentration.

The ferric reducing antioxidant power (FRAP) assay was carried out as described by Raudone et al. [39]. The working FRAP solution included TPTZ $(0.01 \mathrm{M}$ dissolved in $0.04 \mathrm{M}$ $\mathrm{HCl}), \mathrm{FeCl}_{3} \cdot 6 \mathrm{H}_{2} \mathrm{O}(0.02 \mathrm{M}$ in water), and an acetate buffer $(0.3 \mathrm{M}, \mathrm{pH} 3.6)$ at the ratio of 1:1:10. A volume of $3 \mathrm{~mL}$ of a freshly prepared FRAP reagent was mixed with $10 \mu \mathrm{L}$ of the cranberry extract. After $30 \mathrm{~min}$, the absorbance was read at $593 \mathrm{~nm}$ using a UV-vis spectrophotometer. A standard curve $\left(y=0.0000166 x+0.000950 ; R^{2}=0.993\right)$ was produced by using standard Trolox solutions of 400-24,000 $\mu \mathrm{mol} / \mathrm{L}$ concentration.

\subsubsection{Total Anthocyanins Content Determination}

The total anthocyanin content was determined according to the $\mathrm{pH}$ differential method as described by Lee et al. [40]. During the evaluation, $0.625 \mathrm{~mL}$ of cranberry extracts were diluted in $25 \mathrm{~mL}$ of two different buffers: $0.025 \mathrm{M}$ potassium chloride $(\mathrm{pH}=1.0)$ and $0.4 \mathrm{M}$ sodium acetate $(\mathrm{pH}=4.5)$. The samples were kept in the dark for 20 to $30 \mathrm{~min}$ and then the absorption (A) was measured at $\lambda=520 \mathrm{~nm}$ and $\lambda=700 \mathrm{~nm}$. The diluted test portions were read versus a blank cell filled with distilled water.

The anthocyanin pigment concentration, expressed as cyanidin-3-glucoside equivalents, was calculated as follows:

$$
\text { Anthocyanin content }(\mathrm{mg} / \mathrm{L})=\mathrm{A} \times \mathrm{MW} \times \mathrm{DF} \times 1000 /(\varepsilon \times 1)
$$

where: $\mathrm{A}=(\mathrm{A} 520-\mathrm{A} 700)_{\mathrm{pH} 1.0}-(\mathrm{A} 520-\mathrm{A} 700)_{\mathrm{pH} 4.5} ; \mathrm{MW}$ (molecular weight $)=449.2 \mathrm{~g} \mathrm{~mol}^{-1}$ for cyanidin-3-glucoside; $\mathrm{DF}=$ dilution factor; $1=$ cuvette path length in $\mathrm{cm}(1 \mathrm{~cm})$; $\varepsilon=26,900$ mol extinction coefficient, in $\mathrm{L} \times \mathrm{mol}^{-1} \times \mathrm{cm}^{-1}$ for cyanidin-3-glucoside.

\subsection{The UPLC-PDA Method}

The analysis of the qualitative and quantitative composition of anthocyanins in cranberry fruit was performed using the UPLC methodology validated by Vilkickyte et al. [19]. The identification of the peaks was performed by comparing the UV absorption spectrum of the reference standard with the UV absorption spectrum of the matrix peaks of American cranberry, using the same retention time.

\subsection{Statistical Analysis}

Data analysis was performed using Microsoft Excel 2016 (Microsoft, Santa Rosa, CA, USA) and SPSS Statistics 27 (IBM, Armonk, NY, USA). All experiments were carried out in triplicate, and presented as the mean value \pm SD. Significant differences between samples were determined using ANOVA with Tukey's test for multiple comparisons. The variability of the results were evaluated using coefficients of variation (CV). Principal component analysis (PCA) and hierarchical cluster analysis applying the between-groups clustering method with Euclidean distances were performed to elucidate the groupings of cranberries. Correlational analysis was performed using Pearson coefficient. Level of significance $\alpha=0.05$.

\section{Results and Discussion}

3.1. Determination of the Qualitative and Quantitative Composition of Anthocyanins in Cranberry Fruit Samples via the UPLC Method

Increasing consumer awareness creates the demand for the products with healthpromoting effects and capabilities of prevention of various pathological processes. To assure the quality of such products, it is important to study the chemical composition of cranberry fruits and to conduct qualitative and quantitative evaluation of their biologically active compounds [41]. The chromatogram of anthocyanins and anthocyanidins in cranberry fruit samples identified via the UPLC-DAD method is shown in Figure 2. 


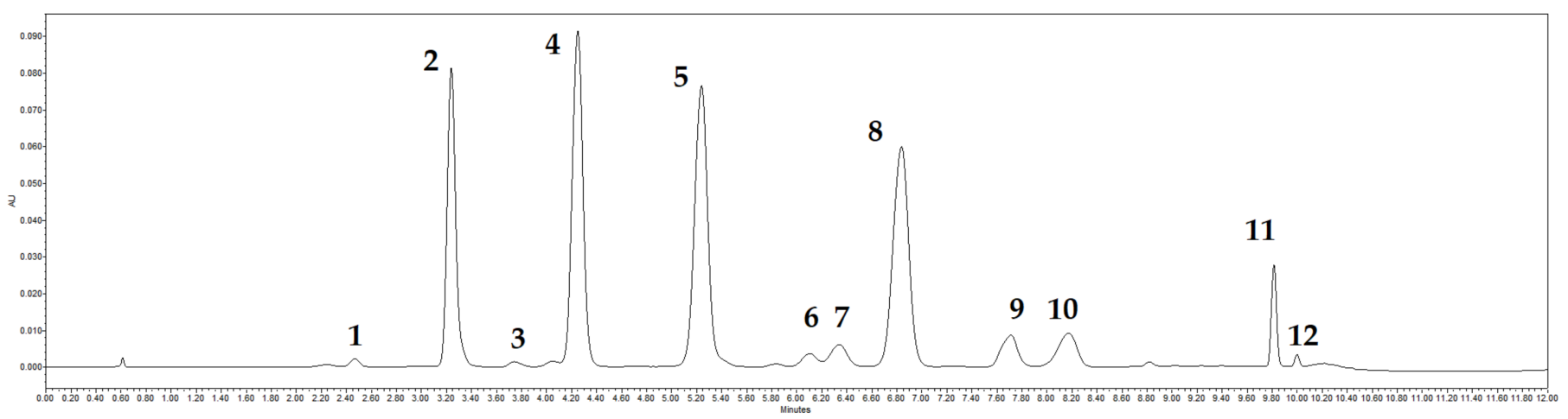

Figure 2. Chromatogram profile of anthocyanins in fruit samples of American cranberries at $520 \mathrm{~nm}$ : 1-Delphinidin-3-galactoside, 2-Cyanidin-3-galactoside, 3-Cyanidin-3-glucoside, 4-Cyanidin3-arabinoside, 5-Peonidin-3-galactoside, 6-Peonidin-3-glucoside, 7-Malvidin-3-galactoside, 8Peonidin-3-arabinoside, 9-Cyanidin, 10-Malvidin-3-arabinoside, 11-Peonidin, 12-Malvidin.

Four anthocyanin glycosides, namely cyanidin-3-galactoside, cyanidin-3-arabinoside, peonidin-3-galactoside, and peonidin-3-arabinoside, predominated in the studied samples of cranberry cultivars grown in Lithuanian (Figure 2) in a range of 15.12-25.41\%, $15.29-25.30 \%, 15.05-37.98 \%$, and $13.25-25.92 \%$, respectively (Figure 3). They accounted for $91.66 \pm 2.79 \%$ of the total amount of anthocyanins identified. The qualitative profiles determined in our study are consistent with the results of Česonienè et al. and Viskelis et al. [7,42] and these compounds could be regarded as anthocyanin marker compounds. However, their quantitative profiles were variable. Česonienè et al. have determined that cyanidin-3-galactoside accounted for $24.11 \%$, cyanidin-3-arabinoside for $18.73 \%$, peonidin-3-galactoside for $33.29 \%$, and peonidin-3-arabinoside for $16.7 \%$ of total determined anthocyanins [42]. Vikelis et al. have determined the following marker compound composition in fruit samples of 'Stevens', 'Pilgrim', 'Ben Lear', and 'Black Veil': cyanidin3 -galactoside $-20.5 \%$, cyanidin-3-arabinoside $-19 \%$, peonidin-3-galactoside $-32.7 \%$, and peonidin-3-arabinoside- $6.7 \%$ of total anthocyanin content [7]. Furthermore, Zhang et al. have studied the composition of fruit wine of cranberry cultivars 'Stevens', 'Pilgrim', and 'Bergman'. The anthocyanin content of cranberry wine has been found to be about $50 \%$ cyanidin-3-arabinoside and about $27 \%$ peonidin-3-arabinoside. The anthocyanin content in the wine of the fruits of other cranberry cultivars have been determined with different compositions, namely of $4 \%$ of cyanidin-3-galactoside, $9 \%$ of peonidin-3-galactoside, $1.5 \%$ of cyanidin-3-glucoside, and 7\% of peonidin-3-glucoside [43].

In our study, the highest amounts of cyanidin-3-galactoside $(1.92 \pm 0.02 \mathrm{mg} / \mathrm{g})$ were determined in cranberry samples of the 'Woolman' cultivar $(p<0.05)$. Statistically significantly lower levels of cyanidin-3-galactoside $(1.36 \pm 0.03 \mathrm{mg} / \mathrm{g}, 1.28 \pm 0.04 \mathrm{mg} / \mathrm{g}$, and $1.21 \pm 0.02 \mathrm{mg} / \mathrm{g}$ ) were found in fruit samples of cranberry cultivars 'Bergman', 'Howes', and 'Le Munyon', respectively. The lowest cyanidin-3-galctoside levels $(0.29 \pm 0.01 \mathrm{mg} / \mathrm{g}$ and $0.38 \pm 0.01 \mathrm{mg} / \mathrm{g}$ ) were determined in the samples of the 'Early Black' cultivar and the 'BL-22' genetic clone, respectively $(p<0.05)$.

The highest content of cyanidin-3-arabinoside $(1.51 \pm 0.01 \mathrm{mg} / \mathrm{g})$ was determined in cranberry samples of the 'Woolman' cultivar $(p<0.05)$. Lower levels of cyanidin-3arabinoside $(1.24 \pm 0.02 \mathrm{mg} / \mathrm{g}, 1.25 \pm 0.02 \mathrm{mg} / \mathrm{g}, 1.22 \pm 0.01 \mathrm{mg} / \mathrm{g}$, and $1.21 \pm 0.02 \mathrm{mg} / \mathrm{g})$ were found in fruit samples of cranberry cultivars 'Crowley', 'Howes', 'Le Munyon', and 'Mc Farlin', respectively. The lowest cyanidin-3-arabinoside content $(0.40 \pm 0.02 \mathrm{mg} / \mathrm{g})$ was found in fruit samples of the 'BL-22' genetic clone $(p<0.05)$. 


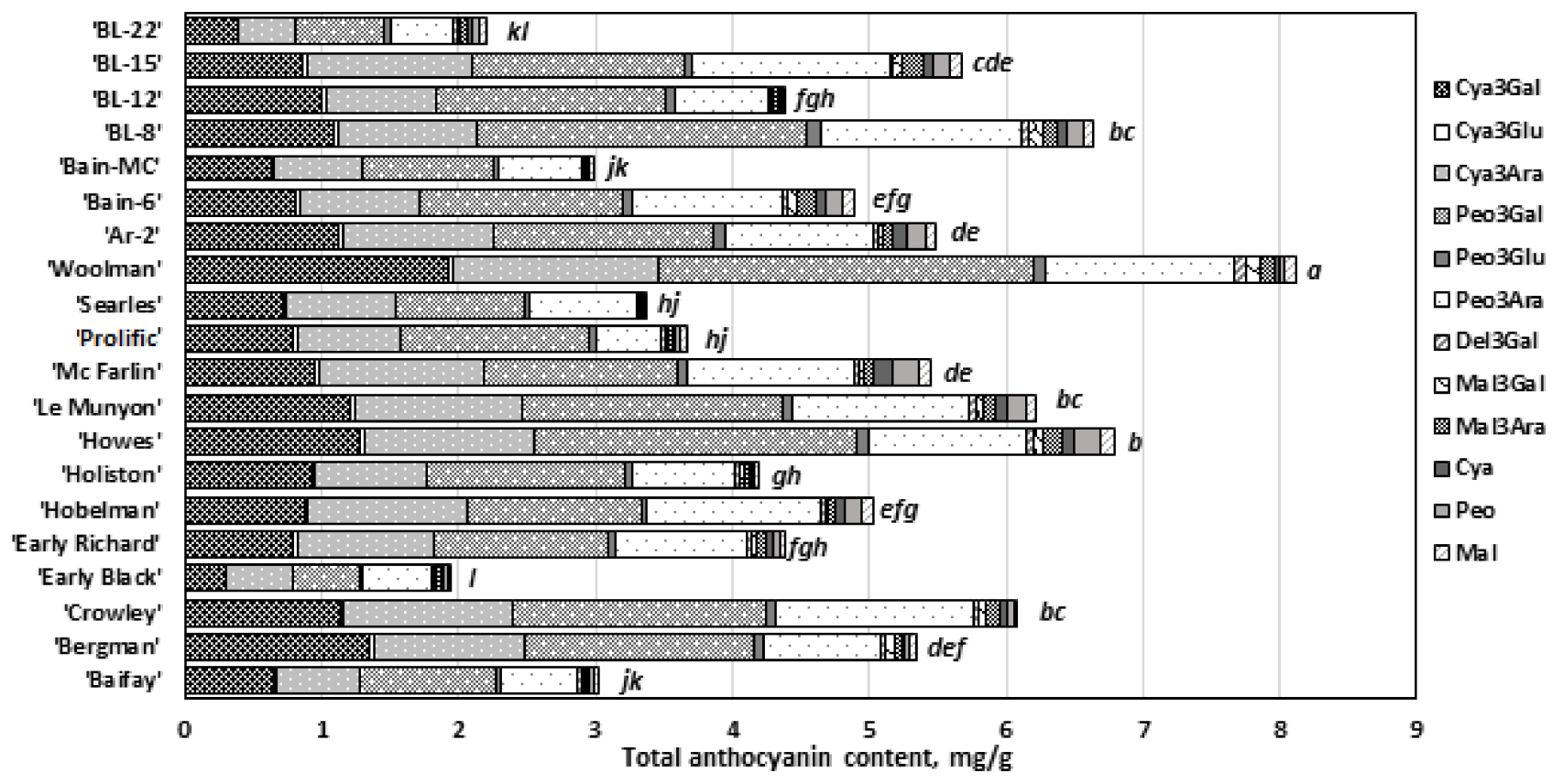

Figure 3. Variation of anthocyanin content in the cranberries of American cultivars. Statistically significant differences between the total anthocyanin content in fruit samples of cranberry cultivars are marked by different letters $(p<0.05)$ : Cya3Gal-Cyanidin-3-galactoside, Cya3Glu-Cyanidin3-glucoside, Cya3Ara-Cyanidin-3-arabinoside, Peo3Gal-Peonidin-3-galactoside, Peo3GluPeonidin-3-glucoside, Peo3Ara-Peonidin-3-arabinoside, Del3Gal-Delphinidin-3-galactoside, Mal3Gal-Malvidin-3-galactoside, Mal3Ara-Malvidin-3-arabinoside, Cya-Cyanidin, PeoPeonidin, Mal-Malvidin.

The highest content of peonidin-3-galactoside $(2.74 \pm 0.03 \mathrm{mg} / \mathrm{g})$ was determined in fruit samples of the 'Woolman' cultivar $(p<0.05)$. Statistically significantly lower levels of peonidin-3-galactoside $(2.35 \pm 0.02 \mathrm{mg} / \mathrm{g}$ and $2.41 \pm 0.03 \mathrm{mg} / \mathrm{g})$ were determined in cranberry samples of the 'Howes' cultivar and the 'BL- 8 ' genetic clone, respectively. The lowest content of peonidin-3-galactoside $(0.49 \pm 0.02 \mathrm{mg} / \mathrm{g})$ was determined in samples of the 'Early Black' cultivar $(p<0.05)$.

The highest levels of peonidine-3-arabinoside $(1.48 \pm 0.02 \mathrm{mg} / \mathrm{g}, 1.38 \pm 0.02 \mathrm{mg} / \mathrm{g}$, and $1.46 \pm 0.02 \mathrm{mg} / \mathrm{g}$ ) were determined in fruit samples of the genetic clone 'BL-8' and 'Woolman' and 'Crowley' cultivars, respectively $(p<0.05)$. The lowest peonidine-3arabinoside levels $(0.50 \pm 0.01 \mathrm{mg} / \mathrm{g}$ and $0.47 \pm 0.02 \mathrm{mg} / \mathrm{g})$ were determined in cranberries of the 'Early Black' cultivar and the 'BL-22' genetic clone, respectively $(p<0.05)$.

The analysis of the quantitative composition of the anthocyanin complex in cranberry fruit samples showed that aglycones formed a small part of the anthocyanin complex. The highest content of one of the anthocyanidins, cyanidin $(0.133 \pm 0.01 \mathrm{mg} / \mathrm{g})$, was determined in fruit samples of the 'McFarlin' cultivar $(p<0.05)$, while no cyanidin was detected in fruit samples of the 'Searles' cultivar. Peonidin content ranged from $0.17 \%$ to $3.53 \%$ in cranberry fruit samples. The highest levels of peonidin $(0.184 \pm 0.01 \mathrm{mg} / \mathrm{g}$ and $0.192 \pm 0.01 \mathrm{mg} / \mathrm{g})$ were found in fruit samples of 'Howes' and 'McFarlin' cultivars, respectively $(p<0.05)$. The lowest aglycone peonidin content $(0.006 \pm 0.00 \mathrm{mg} / \mathrm{g})$ was determined in cranberry samples of the 'Searles' cultivar $(p<0.05)$. Malvidin content ranged from $0.21 \%$ to $2.60 \%$ in cranberry samples. The highest content of the anthocyanidin malvidin $(0.107 \pm 0.01 \mathrm{mg} / \mathrm{g})$ was found in fruit samples of the 'Howes' cultivar, and the lowest $(0.012 \pm 0.00 \mathrm{mg} / \mathrm{g})$ in fruit samples of the 'Crowley' cultivar $(p<0.05)$. These results suggest that genotypes have characteristic variation in the amounts of individual anthocyanins and anthocyanidins.

The highest total anthocyanin content $(8.13 \pm 0.09 \mathrm{mg} / \mathrm{g})$ was determined in cranberry samples of the 'Woolman' cultivar $(p<0.05)$. Lower total anthocyanin levels $(6.90 \pm 0.12 \mathrm{mg} / \mathrm{g}, 6.22 \pm 0.15 \mathrm{mg} / \mathrm{g}, 6.07 \pm 0.08 \mathrm{mg} / \mathrm{g}$, and $6.63 \pm 0.11 \mathrm{mg} / \mathrm{g})$ were 
found in cranberry samples of 'Howes', 'Le Munyon', and 'Crowley' cultivars and in the 'BL-8' genetic clone, respectively. The lowest total anthocyanin levels $(1.95 \pm 0.11 \mathrm{mg} / \mathrm{g}$ and $2.21 \pm 0.15 \mathrm{mg} / \mathrm{g}$ ) were found in fruit samples of the 'Early Black' cultivar and the 'BL-22' genetic clone, respectively $(p<0.05)$.

Gardana et al. have studied the anthocyanin content in fruit samples of 'Ben Lear', 'Howes', 'Stevens', and 'Bergman' cultivars and found that the total anthocyanin content ranged from $2.4 \mathrm{mg} / \mathrm{g}$ to $5.6 \mathrm{mg} / \mathrm{g}$ [44]. The total anthocyanin levels $(5.07 \mathrm{mg} / \mathrm{g}$ in cranberry samples of the 'Howes' cultivar and $3.36 \mathrm{mg} / \mathrm{g}$ in cranberry samples of the 'Bergman' cultivar) that were found by the authors were lower than those found in our study $(6.80 \mathrm{mg} / \mathrm{g}$ and $5.34 \mathrm{mg} / \mathrm{g}$ in fruit samples of the 'Howes' and 'Bergman' cultivars, respectively) [44]. Brown et al. have examined the anthocyanin composition in fruit samples of cultivars 'Ben Lear', 'Bergman', 'GH 1', 'Pilgrims', and 'Stevens' and found that the total anthocyanin content ranged from $2.81 \mathrm{mg} / \mathrm{g}$ to $7.98 \mathrm{mg} / \mathrm{g}$ [45]. The total anthocyanin content that were found by the authors in fruit samples of the 'Bergman' cultivar $(7.02 \mathrm{mg} / \mathrm{g})$ were higher than that found in our study $(5.34 \mathrm{mg} / \mathrm{g})$ [45]. The total anthocyanin content in samples of fresh cranberry fruit of the 'Bergman' and 'Early Richard' cultivars $(0.48 \mathrm{mg} / \mathrm{g}$ and $0.52 \mathrm{mg} / \mathrm{g}$, respectively) were found in a study conducted by Narwojsz et al. to be about 10 times lower than the total anthocyanin levels in the lyophilized raw material of 'Bergman' and 'Early Richard' cultivars found in our study $(4.38 \mathrm{mg} / \mathrm{g}$ and $5.34 \mathrm{mg} / \mathrm{g}$, respectively) [46].

The quantified mean amounts of anthocyanins and anthocyanidins in fruit samples of cranberry cultivars can be presented in the following decreasing order: peonidin-3galactoside $>$ peonidin-3-arabinoside $>$ cyanidin-3-arabinoside $>$ cyanidin-3-galactoside $>$ peonidin $>$ malvidin-3-arabinoside $>$ peonidin-3-glucoside $>$ malvidin $>$ cyanidin $>$ malvidin-3-galactoside $>$ delphinidin-3-galactoside $>$ cyanidin-3-glucoside. The chromatographic profile of cranberry anthocyanins is characteristic, and thus its identification can be applied for establishing the authenticity of the cranberry plant raw material and identifying possible falsifications with other anthocyanin-accumulating botanical raw materials [47].

\subsection{Quantification of the Total Anthocyanin Content in Cranberry Samples}

Spectrophotometric analysis is used to evaluate the quality of herbal raw materials and their preparations. This method is used to assess the quantitative composition of the groups of biologically active compounds. The spectrophotometric $\mathrm{pH}$ differential method is simple, fast, and economical. This method is often used in practice to determine the total anthocyanin content in a sample $[40,48,49]$. The total anthocyanin content determined via the spectrophotometric $\mathrm{pH}$ differential method should be evaluated individually for each plant raw material, as the test results are influenced by the methodology used [50]. The total amount of anthocyanins is usually expressed in CGE (cyanidin-3-glucoside equivalent), as cyanidin-3-glucoside is the predominant anthocyanin in many fruits and vegetables, yet it does not necessarily reflect the anthocyanin composition of the raw material under study [51,52].

The quantitative composition of anthocyanins determined by $\mathrm{pH}$ differential method were analyzed in comparison with the total identified anthocyanin origin compounds determined by the ultra-high performance liquid chromatography method (Table 2).

The total anthocyanin content determined in the studied fruit samples of American cranberries via the $\mathrm{pH}$ differential method ranged from $1.13 \pm 0.02 \mathrm{mg}$ CGE/g to $5.09 \pm 0.24 \mathrm{mg}$ CGE $/ \mathrm{g}$. The lowest total anthocyanin content $(1.13 \pm 0.02 \mathrm{mg}$ CGE $/ \mathrm{g})$ was found in fruit samples of the 'Early Black' cultivar, and the maximum total content of anthocyanins (5.09 $\pm 0.24 \mathrm{mg}$ ) was found in fruit samples of the 'Woolman' cultivar. The total anthocyanin content in the fruit samples of American cranberry cultivars 'Bergman', 'Crowley', 'Howes', 'Le Munyon', and 'McFarlin' grown in New Zealand's climatic conditions ranged from $1.34 \mathrm{mg}$ CGE/g to $1.90 \mathrm{mg}$ CGE/g and were about 1.5 times lower than the total anthocyanin content found in our study in samples of the abovementioned cultivars [53]. 
Table 2. Total anthocyanin content in fruit samples of American cranberry cultivars determined via UPLC and the spectrophotometric $\mathrm{pH}$ differential methods.

\begin{tabular}{ccc}
\hline Cultivar & UPLC $\mathbf{~ m g / g}$ & pH Differential Method \\
\hline 'Baifay' & $3.02 \pm 0.052$ & $1.54 \pm 0.018$ \\
'Bergman' & $5.34 \pm 0.076$ & $3.36 \pm 0.137$ \\
'Crowley' & $6.07 \pm 0.057$ & $3.72 \pm 0.050$ \\
'Early Black' & $1.95 \pm 0.110$ & $1.13 \pm 0.021$ \\
'Early Richard' & $4.38 \pm 0.053$ & $2.67 \pm 0.145$ \\
Hobelman' & $5.03 \pm 0.002$ & $3.10 \pm 0.123$ \\
'Holiston' & $4.19 \pm 0.030$ & $2.30 \pm 0.066$ \\
'Howes' & $6.79 \pm 0.106$ & $4.37 \pm 0.101$ \\
'Le Munyon' & $6.22 \pm 0.077$ & $3.60 \pm 0.149$ \\
'Mc Farlin' & $5.44 \pm 0.026$ & $3.41 \pm 0.116$ \\
'Prolific' & $3.66 \pm 0.002$ & $1.90 \pm 0.089$ \\
'Searles' & $3.37 \pm 0.001$ & $1.86 \pm 0.103$ \\
'Woolman' & $8.13 \pm 0.093$ & $5.09 \pm 0.244$ \\
'Ar-2' & $5.49 \pm 0.010$ & $3.18 \pm 0.010$ \\
'Bain-6' & $4.89 \pm 0.079$ & $2.88 \pm 0.101$ \\
'Bain-MC' & $2.99 \pm 0.016$ & $1.53 \pm 0.073$ \\
'BL-8' & $6.63 \pm 0.070$ & $3.88 \pm 0.030$ \\
'BL-12' & $4.39 \pm 0.001$ & $2.53 \pm 0.078$ \\
'BL-15' & $5.67 \pm 0.073$ & $3.57 \pm 0.244$ \\
'BL-22' & $2.21 \pm 0.088$ & $1.41 \pm 0.002$ \\
\hline
\end{tabular}

The total anthocyanin content in cranberry fruit samples determined via the $\mathrm{pH}$ differential method was about 1.6 times lower than the total anthocyanin content determined via the UPLC method. The coefficient of variation of the total anthocyanin content in cranberry fruit samples determined via the UPLC method was $33.57 \%$, while that determined via the $\mathrm{pH}$ differential method was $37.45 \%$.

Grace et al. in their study have found that the total anthocyanin content (expressed as CGE) in American cranberry fruit samples detected via the application of the $\mathrm{pH}$ differential method was 1.4 times lower than that detected via the HPLC method [54]. Lee et al. have found no statistically significant difference between the anthocyanin content in cranberry samples determined via the $\mathrm{pH}$ differential method (1.95 $\pm 0.14 \mathrm{mg}$ CGE/g) and the UPLC method (2.06 $\pm 0.26 \mathrm{mg} \mathrm{CGE} / \mathrm{g}$ ) [55]. The authors did not find any differences between the compared methods because the total amount of anthocyanins was calculated based on the four predominant anthocyanins, namely cyanidin-3-galactoside, cyanidin-3-arabinoside, peonidin-3-galactoside, and peonidin-3-arabinoside, whereas in our study, the amount of other anthocyanins detected in cranberry fruit samples ranged from $3.71 \%$ to $13.23 \%$ [55].

The results obtained using $\mathrm{pH}$ differential methods and UPLC were highly corresponding and correlated $(\mathrm{R}=0.975, p<0.05)$. A very strong significant correlation between the total anthocyanin content in cranberry fruit samples assessed via the $\mathrm{pH}$ differential method and the UPLC method was also found in other studies, the correlation coefficients being $\mathrm{r}=0.98, \mathrm{r}=0.925$, and $\mathrm{r} \geq 0.99(p<0.05)[50,54,55]$. The very strong correlation between the $\mathrm{pH}$ differential method and the UPLC method indicates that the anthocyanin content determined by both methods is similar, but the results obtained should be evaluated on a case-by-case basis, depending on the raw material and the nature of the study.

\subsection{Hierarchical Cluster Analysis and Principal Component Analysis of the Distribution of Anthocyanin Content in Fruit Samples of American Cranberry}

The analysis of the similarity of the composition of anthocyanins in American cranberry cultivars introduced and grown in Lithuanian climatic conditions was based on the quantitative composition of anthocyanins determined in the samples of different cultivars and was carried out by performing a hierarchical cluster and principal component analysis. The cluster analysis of the samples of different cultivars of American cranberry was performed on the basis of the quantitative composition of antho- 
cyanins delphinidin-3-galactoside, cyanidin-3-galactoside, cyanidin-3-glucoside, cyanidin3-arabinoside, peonidine-3-galactoside, peonidin-3-glucoside, peonidin-3-galactoside, peon idine-3-arabinoside, cyanidin, malvidin-3-arabinoside, peonidin, and malvidin. Fruit samples of cranberry cultivars were divided into three clusters (Figure 4).

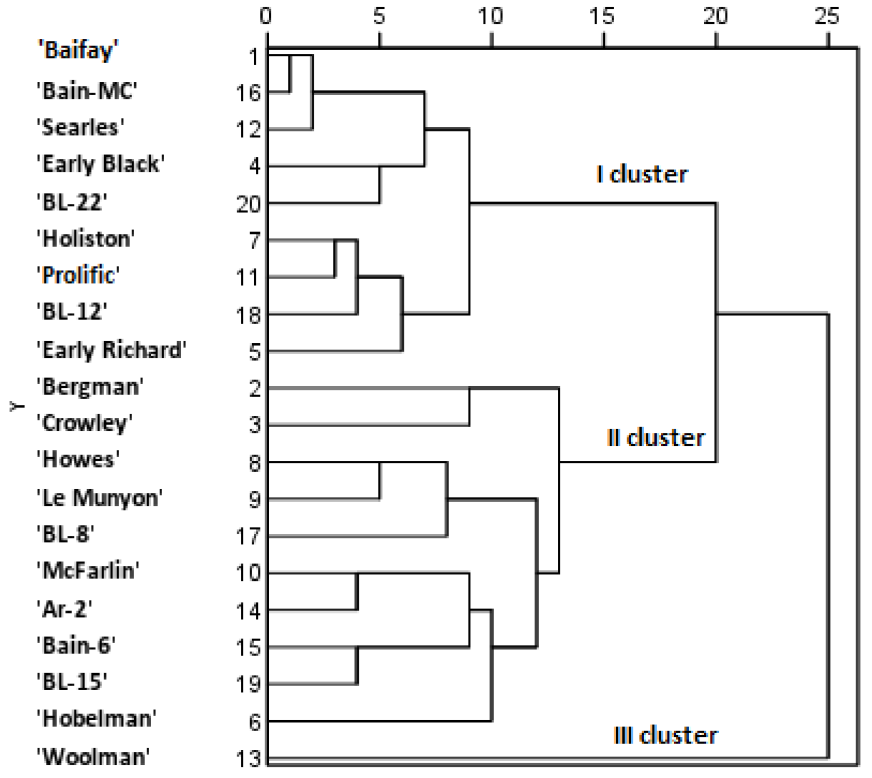

(a)

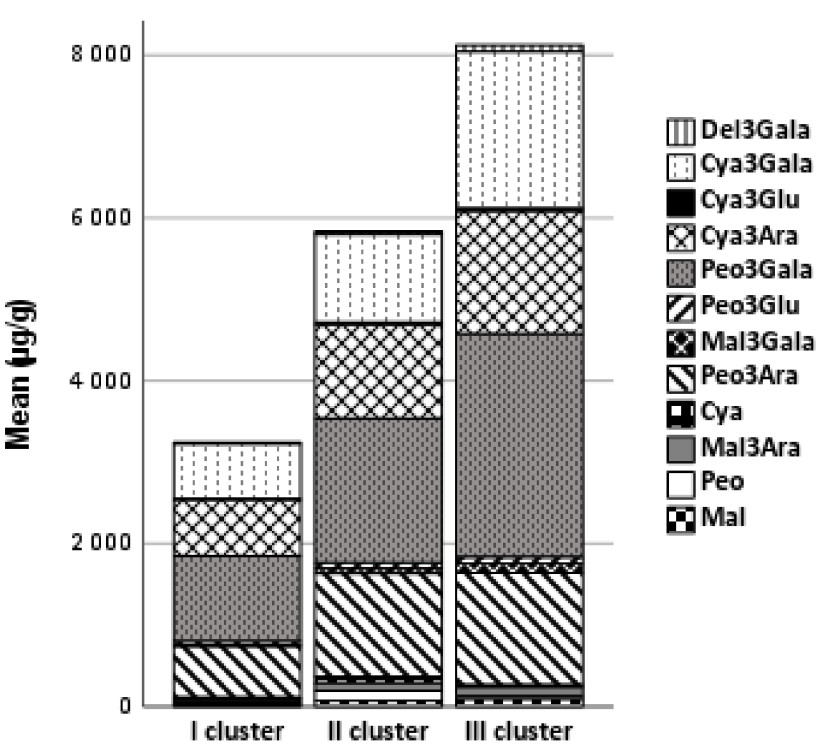

(b)

Figure 4. A dendrogram of the distribution of American cranberry cultivars into similar clusters according to the anthocyanin content in fruit samples (a); a diagram of the distribution of mean anthocyanin content in clusters (b). Cya3Gala-Cyanidin-3-galactoside, Cya3Glu-Cyanidin3-glucoside, Cya3Ara-Cyanidin-3-arabinoside, Peo3Gala-Peonidin-3-galactoside, Peo3GluPeonidin-3-glucoside, Peo3Ara-Peonidin-3-arabinoside, Del3Gala-Delphinidin-3-galactoside, Mal3Gala-Malvidin-3-galactoside, Mal3Ara-Malvidin-3-arabinoside, Cya-Cyanidin, PeoPeonidin, Mal-Malvidin.

Fruit samples of cranberry cultivars 'Baifay', 'Early Black', 'Early Richard', 'Holiston', 'Prolific', 'Searles', 'Bain-6', 'BL-12', and 'BL-22' were assigned to cluster I because their total anthocyanin content was by 1.7 times lower than the average total anthocyanin content. The total amount of anthocyanins found in the fruit samples of the cluster II cultivars ('Bergman' 'Crowley', 'Hobelman', 'Howes', 'Le Munyon', 'Mc Farlin', 'Ar-2', 'Bain-MC', 'BL-8', and 'BL-15') was close to the mean anthocyanin content. Cluster II is considered to consist of cranberry cultivar samples which have higher than average levels of anthocyanidins (cyanidin, peonidin, and malvidin). Cluster III consisted of one American cranberry cultivar 'Woolman'. The total anthocyanin content in cranberry fruit samples of the 'Woolman' cultivar was twice the mean total anthocyanin content in the studied cultivars.

A principal component analysis (PCA) was performed to evaluate the quantitative variation of the identified anthocyanin group compounds in different American cranberry cultivars (Figure 5). Two main components were used for the analysis, explaining $85.82 \%$ of the total data variance. The first component (PC I), which explained $52.18 \%$ of the total data variance, had a significant correlation with the anthocyanin galactosides cyanidin-3-galactoside (0.958), peonidin-3-galactoside (0.942), delphinidin-3-galactoside (0.926), and malvidin-3galactoside (0.881), and a strong positive correlation with cyanidin-3-arabinoside (0.786), cyanidin-3-glucoside (0.781), peonidin-3-glucoside (0.759), and peonidin-3-arabinoside (0.658). The second component (PC II), which explained $33.64 \%$ of the total data variance, had a significant correlation with cyanidin (0.973) and peonidin (0.973), and a positive correlation with malvidin (0.738) and malvidin-3-arabinoside (0.613). 


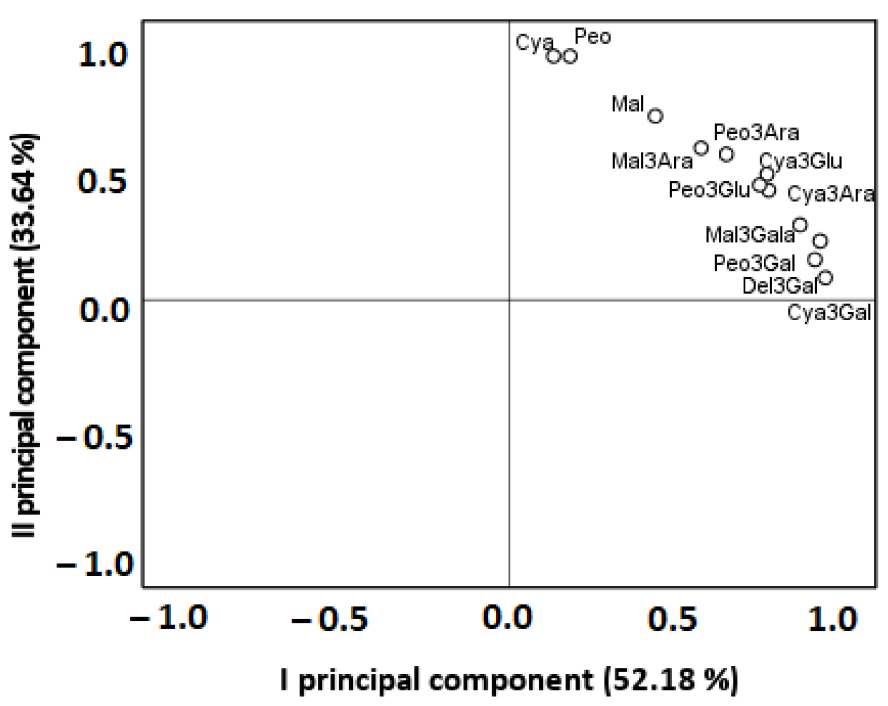

(a)

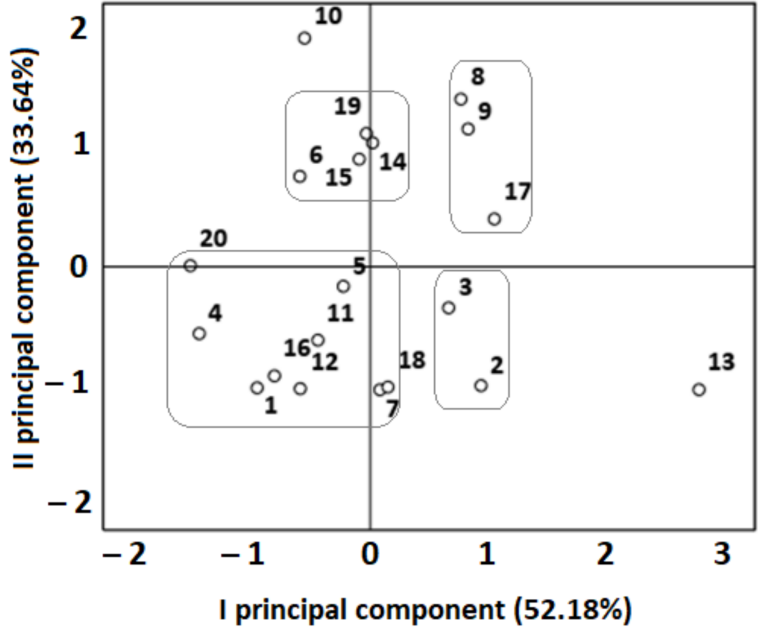

(b)

Figure 5. Principal component analysis loading (a) and score (b) plots of different cranberry fruit samples: (a) Cya3Gala-Cyanidin-3-galactoside, Cya3Glu-Cyanidin-3-glucoside, Cya3Ara-Cyanidin-3arabinoside, Peo3Gal-Peonidin-3-galactoside, Peo3Glu-Peonidin-3-glucoside, Peo3Ara-Peonidin3-arabinoside, Del3Gal-Delphinidin-3-galactoside, Mal3Gala-Malvidin-3-galactoside, Mal3AraMalvidin-3-arabinoside, Cya-Cyanidin, Peo-Peonidin, Mal-Malvidin; (b) 1-'Baifay', 2'Bergman', 3-'Crowley', 4-'Early Black', 5-'Early Richard', 6-'Hobelman', 7-'Holiston', 8'Howes', 9-'Le Munyon', 10-'Mc Farlin', 11-'Prolific', 12-'Searles', 13-'Woolman', 14-'Ar-2', 15-'Bain-MC', 16-'Bain-6', 17-'BL-8', 18-'BL-12', 19-'BL-15', 20-'BL-22'.

American cranberry cultivars located in the negative squares of PC I and PC II ('Baifay', 'Early Black', 'Early Richard', 'Holiston', 'Prolific', 'Searles', 'Bain-6', 'BL-12', and 'BL-22') coincided with cluster I in the cluster analysis, which had a lower-than-average total anthocyanin content. The cranberry cultivars 'Bergman' and 'Crowley' formed the second group of similar cultivars with above-average total anthocyanin content and below-average total anthocyanidin (cyanidin, peonidin, and malvidin) content. The total anthocyanin content in the samples of the hybrid cultivars 'Bergman' (a hybrid of 'Early Black' and 'Searles') and 'Crowley' (a hybrid of 'Mc Farlin' and 'Prolific') was higher than that in samples of the precursor cultivars 'Early Black' and 'Searles', and 'Mc Farlin' and 'Prolific', respectively. Diaz-Garcia et al. found that fruit samples of the second- and third-generation cycle cultivars contained higher levels of anthocyanins than the samples of the early selection attempts did [56].

The American cranberry cultivar 'Woolman' was far removed from other cranberry cultivars in the PCA chart because the total anthocyanin content found in it was almost two times higher than the mean total anthocyanin content. Exceptionally high levels of cyanidin-3-galactoside and peonidin-3-galactoside were determined in samples of the cranberry cultivar 'Woolman', but the total content of anthocyanidins (cyanidin, peonidin, and malvidin) was lower than their mean total content in cultivar samples. In our previously published study, samples of the cranberry cultivar 'Woolman' differed from samples of cultivars 'Baiwfay', 'Drever', 'Bain', 'Bergman', 'Searles', 'Holliston', and 'Piligrim' in that they contained high levels of phenolic acids and dihydrochalcones and low levels of flavonols and flavan-3-ols [32].

The total content of anthocyanidin galactosides in fruit samples of the group consisting of the cranberry cultivar 'Hobelman' and genetic clones 'Ar-2', 'Bain-MC', and 'BL-15' was close to the mean total amount of galactosides in the studied cultivars, and the total content of anthocyanidins (cyanidin, peonidin, and malvidin) was higher than the mean total amount of anthocyanidins. The cranberry cultivar 'Mc Farlin' was far from other cultivars 
in the PCA chart because its fruit samples contained two times the average amount of aglycones (cyanidin, peonidin, and malvidin). The group of American cranberry cultivars 'Howes', 'Le Munyon', and 'BL-8' located in the positive quadrant of PC I and PC II was characterized by higher anthocyanidin galactoside and total anthocyanidin contents compared to the mean total anthocyanidin and galactoside contents.

\subsection{Determination of Antioxidant Activity}

Recently, many studies have been conducted on phenolic compounds in plant matrices as natural antioxidants with protective antioxidant properties as well as on the application of these phenolic compounds for prophylactic purposes [57]. The antioxidant effects of anthocyanins occur through a number of complex mechanisms by which anthocyanins can directly scavenge free radicals, prevent the formation of reactive oxygen species (by forming chelating compounds with metals, they inhibit redox reactions and inhibit xanthine oxidase and NADPH oxidase), or promote the release of antioxidant enzymes $[58,59]$. The antioxidant properties of phenolic compounds are associated with biological effects such as anti-inflammatory, anticancer, and antimicrobial effects. In vitro assays for antiradical and reductive activity are expedient to determine the potency of the potential antioxidant activity of the extracts of fruit samples of the tested cultivars.

The strongest antiradical activity detected by using the ABTS method (849.75 \pm $10.88 \mu \mathrm{mol} \mathrm{TE} / \mathrm{g}$ ) was found in samples of the cranberry cultivar 'Woolman' (Figure 6). The strongest antioxidant activity determined by using the FRAP method (528.05 \pm $12.16 \mu \mathrm{mol} \mathrm{TE} / \mathrm{g}$ ) was determined in samples of the cranberry cultivar 'Le Munyon'. The weakest antiradical activity detected by applying the ABTS method $(203.20 \pm 9.19 \mu \mathrm{mol} \mathrm{TE} / \mathrm{g})$ was determined in samples of the cranberry cultivar 'Baifay'. The weakest reducing activity $(215.23 \pm 3.24 \mu \mathrm{mol} \mathrm{TE} / \mathrm{g})$ was found in fruit samples of the 'Prolific' cultivar.

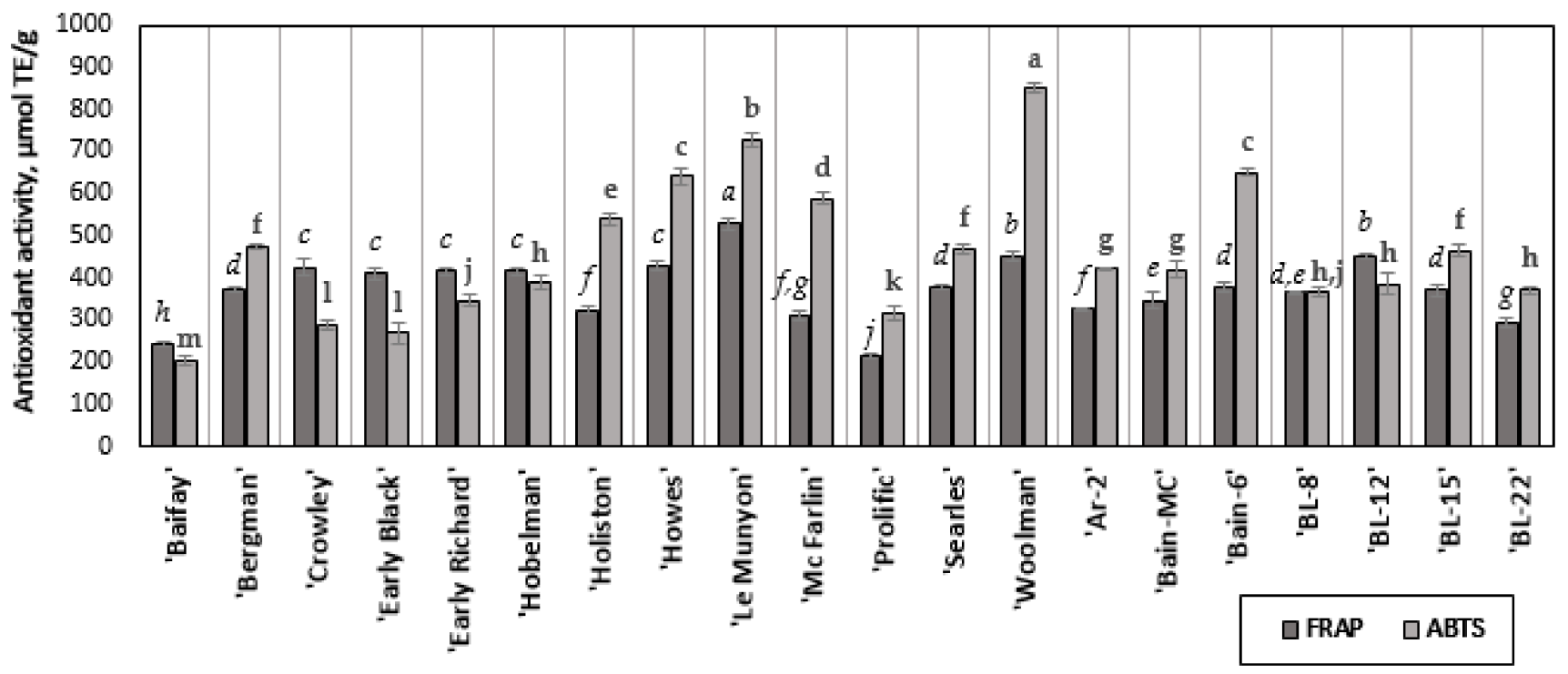

Figure 6. Determination of the antioxidant activity of cranberry extracts. The letters of different fonts indicate statistically significant differences in the antioxidant activity of the fruit extracts of cranberry cultivars determined by the FRAP and ABTS methods $(p<0.05)$.

Oszmiański et al. have investigated the antioxidant activity of fruit extracts of 'Howes' by applying the ABTS and FRAP methods [5]. However, in our study, the reducing and radical scavenging activities of 'Howes' fruit extracts were 4-fold and 3-fold greater, respectively.

The correlation between the total anthocyanin content and antioxidant capacity was determined for the ABTS method $(\mathrm{r}=0.635 ; p<0.001)$, and for the FRAP method $(\mathrm{r}=0.507$; $p<0.001)$. Oszmiański et al. determined similar correlation coefficients for the ABTS 
( $r=0.675)$, FRAP $(r=0.614)$, and DPPH $(r=0.602)$ methods. Chaves et al. have found that the total anthocyanin content determined in the samples of blackberries, blueberries, and strawberries correlated with the antiradical capacity of the extracts determined by the DPPH and ABTS methods (respectively, $r=0.86, r=0.82$ ) [60]. The positive correlation of anthocyanin content with antioxidant activity suggests that these compounds may contribute to the antioxidant effects of fruit extracts. The American cranberries, besides the great fraction of anthocyanins, also contain other phenolic origin compounds such as flavonoids, phenolic acids, and proanthocyanidins [47]. The anthocyanins together with other phenolic compounds present in the extracts express the total antioxidant activity of the extract.

Scientific studies confirm that antioxidant activity mechanisms are interrelated with the biological activities expressed in the body and substantiates that the bioavailability of phenolic compounds is highly important for their bioactivities in vivo [61]. The data in the literature show that, after ingestion, anthocyanins are quickly absorbed through the stomach and the small intestine by various mechanisms [62]. Nevertheless, small amounts of anthocyanins are absorbed, and plasma levels of cranberry anthocyanins appear to be too low to compete effectively with antioxidants such as ascorbate and glutathione [63]. However, the unabsorbed part of anthocyanins reach the colon, where they can modulate the microbiota $[62,63]$. Consumption of anthocyanins can modify the colonization of the gut microbiota by the stimulation of the growth of beneficial bacteria, such as Bifidobaterium spp. and Lactobacillus spp., and the inhibition the growth of pathogenic bacteria, such as Staphylococcus aureus and Salmonella typhimurium $[62,64]$. Gutpaper et al. showed that obese mice with a diet of $200 \mathrm{mg} / \mathrm{kg}$ cranberry extract per 8 weeks increased the Akkermansia population and induced features of the prevention of metabolic phenotypes linked to obesity. Furthermore, treatment with cranberry extract was found to lower content of intestinal triglyceride and to reduce inflammation and oxidative stress of the intestinal tract [65]. The beneficial effects of anthocyanins could be related to the effects on the intestinal tract, which are important for various biochemical processes in the body.

\section{Conclusions}

Cranberry's phytochemical profile is genotype-dependent and this study provides new knowledge on the variation in the composition of anthocyanins and anthocyanidins in different cranberry cultivars. Moreover, this study allows for the assessment of the quality of cranberry fruit and the use of high-quality cranberry raw material for food and health promotion. Four anthocyanin compounds predominated in fruit samples of American cranberry cultivars: cyanidin-3-galactoside, cyanidin-3-arabinoside, peonidin-3-galactoside, and peonidin-3-arabinoside, and they can be regarded as qualitative profile markers of American cranberry products. The chromatographic profiles are species-characteristic and can be applied for cranberry authenticity studies.

The fruits of American cranberry cultivars 'Woolman' and 'Le Munyon' distinguished with the highest content of anthocyanins, and their extracts had the strongest antioxidant activity. The cultivation of cranberry cultivars 'Woolman', 'Howes', and 'Le Munyon' in Lithuanian climatic conditions could be carried out in gardens and collections. The results of this study allow for evaluating the qualitative and quantitative composition of anthocyanins and anthocyanidins in fruit samples of the grown cultivars and for ensuring the preparation of high-quality cranberry raw material. High-quality phytochemically characterized American cranberry extracts rich in natural antioxidants can be used in the production of high-added-value products, food supplements, and other functional ingredients for nutrition and health.

Author Contributions: Conceptualization V.J. and L.R.; methodology L.R. and R.U.; software R.U. and L.R.; formal analysis R.U., investigation R.U., L.R. and V.J., resources R.U., L.R. and V.J.; data curation V.J. and L.R.; writing — original draft preparation R.U.; writing—review and editing V.J. and L.R., visualization R.U.; supervision V.J. and L.R.; project administration V.J. All authors have read and agreed to the published version of the manuscript. 
Funding: This research received no external funding.

Institutional Review Board Statement: Not applicable.

Informed Consent Statement: Not applicable.

Data Availability Statement: All datasets generated for this study are included in the article.

Conflicts of Interest: The authors declare no conflict of interest.

\section{References}

1. McMahan, E.; Guédot, C. Development of Sparganothis sulfureana (Lepidoptera: Tortricidae) on cranberry cultivars. Insects 2018, 9, 4. [CrossRef] [PubMed]

2. Jurikova, T.; Skrovankova, S.; Mlcek, J.; Balla, S.; Snopek, L. Bioactive compounds, antioxidant activity, and biological effects of european cranberry (Vaccinium oxycoccos). Molecules 2018, 24, 24. [CrossRef] [PubMed]

3. Hoekstra, B.R.; Neill, C.; Kennedy, C.D. Trends in the Massachusetts cranberry industry create opportunities for the restoration of cultivated riparian wetlands. Restor. Ecol. 2020, 28, 185-195. [CrossRef]

4. Vorsa, N.; Zalapa, J. Domestication, genetics, and genomics of the American cranberry. Plant Breed. Rev. 2019, 43, $279-315$.

5. Oszmiański, J.; Kolniak-Ostek, J.; Lachowicz, S.; Gorzelany, J.; Matłok, N. Phytochemical compounds and antioxidant activity in different cultivars of cranberry (Vaccinium macrocarpon L). J. Food Sci. 2017, 82, 2569-2575. [CrossRef]

6. Cranberry Production in 2019. UN Food and Agriculture Organization, Corporate Statistical Database. 2020. Available online: https: / /www.fao.org/faostat/en/\#compare (accessed on 20 December 2021).

7. Viskelis, P.; Rubinskienè, M.; Jasutienè, I.; Šarkinas, A.; Daubaras, R.; Česonienė, L. Anthocyanins, antioxidative, and antimicrobial properties of American cranberry (Vaccinium macrocarpon Ait.) and their press cakes. J. Food Sci. 2009, 74, 157-161. [CrossRef]

8. Daubaras, R.; Česonienè, L. Stambiauogiu Spanguolių Pramoniniu Plantaciju Eksploatavimas; Versus Aureus: Vilnius, Lithuania, 2015; pp. 1-40.

9. Gupta, P.; Song, B.; Neto, C.; Camesano, T.A. Atomic force microscopy-guided fractionation reveals the influence of cranberry phytochemicals on adhesion of Escherichia coli. Food Funct. 2016, 7, 2655-2666. [CrossRef]

10. Xue, H.; Tan, J.; Li, Q.; Cai, X.; Tang, J. Optimization ultrasound-assisted extraction of anthocyanins from cranberry using response surface methodology coupled with genetic algorithm and identification anthocyanins with HPLC-MS. J. Food Process. Preserv. 2021, 45, 15378. [CrossRef]

11. Abeywickrama, G.; Debnath, S.C.; Ambigaipalan, P.; Shahidi, F. Phenolics of selected cranberry genotypes (Vaccinium macrocarpon Ait.) and their antioxidant efficacy. J. Agric. Food Chem. 2016, 64, 9342-9351. [CrossRef]

12. Murphy, B.T.; MacKinnon, S.L.; Yan, X.; Hammond, G.B.; Vaisberg, A.J.; Neto, C.C. Identification of triterpene hydroxycinnamates with in vitro antitumor activity from whole cranberry fruit (Vaccinium macrocarpon). J. Agric. Food Chem. 2003, 51, 3541-3545. [CrossRef]

13. Liu, H.; Howell, A.B.; Zhang, D.J.; Khoo, C. A randomized, double-blind, placebo-controlled pilot study to assess bacterial anti-adhesive activity in human urine following consumption of a cranberry supplement. Food Funct. 2019, 10, 7645-7652. [CrossRef] [PubMed]

14. Shaheen, G.; Ahmad, I.; Mehmood, A.; Akhter, N.; Usmanghani, K.; Shamim, T.; Shah, S.M.A.; Sumreen, L.; Akram, M. Monograph of Vaccinium macrocarpon. J. Med. Plants Res. 2011, 5, 5340-5346.

15. Prasain, J.K.; Grubbs, C.; Barnes, S. Cranberry anti-cancer compounds and their uptake and metabolism: An updated review. J. Berry Res. 2020, 10, 1-10. [CrossRef]

16. Wang, Y.; Han, A.; Chen, E.; Singh, R.K.; Chichester, C.O.; Moore, R.G.; Singh, A.P.; Vorsa, N. The cranberry flavonoids PAC DP-9 and quercetin aglycone induce cytotoxicity and cell cycle arrest and increase cisplatin sensitivity in ovarian cancer cells. Int. J. Oncol. 2015, 46, 1924-1934. [CrossRef] [PubMed]

17. Rauf, A.; Imran, M.; Khan, I.A.; Ur-Rehman, M.; Gilani, S.A.; Mehmood, Z.; Mubarak, M.S. Anticancer potential of quercetin: A comprehensive review: Quercetin as an anticancer agent. Phytother. Res. 2018, 32, 2109-2130. [CrossRef] [PubMed]

18. Pappas, E.; Schaich, K.M. Phytochemicals of cranberries and cranberry products: Characterization, potential health effects, and processing stability. Crit. Rev. Food Sci. Nutr. 2009, 49, 741-781. [CrossRef] [PubMed]

19. Vilkickyte, G.; Motiekaityte, V.; Vainoriene, R.; Liaudanskas, M.; Raudone, L. Development, validation, and application of UPLC-PDA method for anthocyanins profiling in Vaccinium L. berries. J. Berry Res. 2021, 11, 583-599. [CrossRef]

20. Yan, X.; Murphy, B.T.; Hammond, G.B.; Vinson, J.A.; Neto, C.C. Antioxidant activities and antitumor screening of extracts from cranberry fruit (Vaccinium macrocarpon). J. Agric. Food Chem. 2002, 50, 5844-5849. [CrossRef]

21. Ho, M.-L.; Chen, P.-N.; Chu, S.-C.; Kuo, D.-Y.; Kuo, W.-H.; Chen, J.-Y.; Hsieh, Y.-S. Peonidin 3-glucoside inhibits lung cancer metastasis by downregulation of proteinases activities and mapk pathway. Nutr. Cancer 2010, 62, 505-516. [CrossRef]

22. Smeriglio, A.; Barreca, D.; Bellocco, E.; Trombetta, D. Chemistry, pharmacology and health benefits of anthocyanins: Anthocyanins and human health. Phytother. Res. 2016, 30, 1265-1286. [CrossRef]

23. Seeram, N. Cyclooxygenase inhibitory and antioxidant cyanidin glycosides in cherries and berries. Phytomedicine 2001, 8, 362-369. [CrossRef] [PubMed] 
24. Glisan, S.L.; Ryan, C.; Neilson, A.P.; Lambert, J.D. Cranberry extract attenuates hepatic inflammation in high-fat-fed obese mice. J. Nutr. Biochem. 2016, 37, 60-66. [CrossRef] [PubMed]

25. Santana, D.G.; Oliveira, A.S.; de Santana Souza, M.T.; do Carmo Santos, J.T.; Hassimotto, N.M.A.; de Oliveira e Silva, A.M.; Grespan, R.; Camargo, E.A. Vaccinium macrocarpon Aiton extract ameliorates inflammation and hyperalgesia through oxidative stress inhibition in experimental acute pancreatitis. Evid.-Based Complement. Altern. Med. 2018, 2018, 1-13. [CrossRef] [PubMed]

26. Seeram, N.P.; Adams, L.S.; Hardy, M.L.; Heber, D. Total cranberry extract versus its phytochemical constituents: Antiproliferative and synergistic effects against human tumor cell lines. J. Agric. Food Chem. 2004, 52, 2512-2517. [CrossRef] [PubMed]

27. Stobnicka, A.; Gniewosz, M. Antimicrobial protection of minced pork meat with the use of swamp cranberry (Vaccinium oxycoccos L.) fruit and pomace extracts. J. Food Sci. Technol. 2018, 55, 62-71. [CrossRef]

28. Cortez, R.; Luna-Vital, D.A.; Margulis, D.; Gonzalez de Mejia, E. Natural Pigments: Stabilization Methods of Anthocyanins for Food Applications. Compr. Rev. Food Sci. Food Saf. 2017, 16, 180-198. [CrossRef]

29. Bechtold, T.; Mahmud-Ali, A.; Mussak, R. Anthocyanin dyes extracted from grape pomace for the purpose of textile dyeing. J. Sci. Food Agric. 2007, 87, 2589-2595. [CrossRef]

30. Singh, S.; Gaikwad, K.K.; Lee, Y.S. Anthocyanin-A natural dye for smart food packaging systems. Korean J. Packag. Sci. Technol. 2018, 24, 167-180. [CrossRef]

31. The Meteorological Data in 2020, Lithuanian Hydrometeorological Service, Monthly Overview of Hydrometeorological Conditions. Available online: http:/ / www.meteo.lt/lt/2021-gruodis (accessed on 22 January 2021).

32. Gudžinskaitè, I.; Stackevičienè, E.; Liaudanskas, M.; Zymonė, K.; Žvikas, V.; Viškelis, J.; Urbštaitè, R.; Janulis, V. Variability in the qualitative and quantitative composition and content of phenolic compounds in the fruit of introduced American cranberry (Vaccinium macrocarpon Aiton). Plants 2020, 9, 1379. [CrossRef]

33. Council of Europe. European Pharmacopoeia, 10th ed.; Council of Europe: Strasbourg, France, 2019; p. 51.

34. Fajardo, D.; Morales, J.; Zhu, H.; Steffan, S.; Harbut, R.; Bassil, N.; Hummer, K.; Polashock, J.; Vorsa, N.; Zalapa, J. Discrimination of American cranberry cultivars and assessment of clonal heterogeneity using microsatellite markers. Plant Mol. Biol. Rep. 2013, 31, 264-271. [CrossRef]

35. Novy, R.G.; Vorsa, N.; Kobak, C.; Goffreda, J. RAPDs identify varietal misclassification and regional divergence in cranberry [Vaccinium macrocarpon (Ait.) Pursh]. Theor. Appl. Genet. 1994, 88, 1004-1010. [CrossRef] [PubMed]

36. Schlautman, B.; Covarrubias-Pazaran, G.; Rodriguez-Bonilla, L.; Hummer, K.; Bassil, N.; Smith, T.; Zalapa, J. Genetic diversity and cultivar variants in the NCGR cranberry (Vaccinium macrocarpon Aiton) collection. J. Genet. 2018, 97, 1339-1351. [CrossRef]

37. Re, R.; Pellegrini, N.; Proteggente, A.; Pannala, A.; Yang, M.; Rice-Evans, C. Antioxidant activity applying an improved ABTS radical cation decolorization assay. Free Radic. Biol. Med. 1999, 26, 1231-1237. [CrossRef]

38. Raudone, L.; Vilkickyte, G.; Pitkauskaite, L.; Raudonis, R.; Vainoriene, R.; Motiekaityte, V. Antioxidant activities of Vaccinium vitisidaea L. leaves within cultivars and their phenolic compounds. Molecules 2019, 24, 844. [CrossRef] [PubMed]

39. Raudone, L.; Raudonis, R.; Liaudanskas, M.; Janulis, V.; Viskelis, P. Phenolic antioxidant profiles in the whole fruit, flesh and peel of apple cultivars grown in Lithuania. Sci. Hortic. 2017, 216, 186-192. [CrossRef]

40. Lee, J.; Durst, R.W.; Wrolstad, R.E. Determination of total monomeric anthocyanin pigment content of fruit juices, beverages, natural colorants, and wines by the ph differential method: Collaborative study. J. AOAC Int. 2005, 88, 1269-1278. [CrossRef]

41. Pourmasoumi, M.; Hadi, A.; Najafgholizadeh, A.; Joukar, F.; Mansour-Ghanaei, F. The effects of cranberry on cardiovascular metabolic risk factors: A systematic review and meta-analysis. Clin. Nutr. 2020, 39, 774-788. [CrossRef]

42. Česonienè, L.; Daubaras, R.; Jasutienè, I.; Venclovienè, J.; Miliauskienè, I. Evaluation of the biochemical components and chromatic properties of the juice of Vaccinium macrocarpon Aiton and Vaccinium oxycoccos L. Plant. Foods Hum. Nutr. 2011, 66, 238-244. [CrossRef]

43. Zhang, J.; Chen, D.; Chen, X.; Kilmartin, P.; Quek, S.Y. The influence of vinification methods and cultivars on the volatile and phenolic profiles of fermented alcoholic beverages from cranberry. Antioxidants 2019, 8, 144. [CrossRef]

44. Gardana, C.; Scialpi, A.; Fachechi, C.; Simonetti, P. Identification of markers for the authentication of cranberry extract and cranberry-based food supplements. Heliyon 2020, 6, e03863. [CrossRef]

45. Brown, P.N.; Murch, S.J.; Shipley, P. Phytochemical diversity of cranberry (Vaccinium macrocarpon Aiton) cultivars by anthocyanin determination and metabolomic profiling with chemometric analysis. J. Agric. Food Chem. 2012, 60, 261-271. [CrossRef] [PubMed]

46. Narwojsz, A.; Tańska, M.; Mazur, B.; Borowska, E.J. Fruit physical features, phenolic compounds profile and inhibition activities of cranberry cultivars (Vaccinium macrocarpon) compared to wild-grown cranberry (Vaccinium oxycoccus). Plant Foods Hum. Nutr. 2019, 74, 300-306. [CrossRef] [PubMed]

47. Mannino, G.; Di Stefano, V.; Lauria, A.; Pitonzo, R.; Gentile, C. Vaccinium macrocarpon (cranberry)-based dietary supplements: Variation in mass uniformity, proanthocyanidin dosage and anthocyanin profile demonstrates quality control standard needed. Nutrients 2020, 12, 992. [CrossRef] [PubMed]

48. Wang, S.Y.; Stretch, A.W. Antioxidant capacity in cranberry is influenced by cultivar and storage temperature. J. Agric. Food Chem. 2001, 49, 969-974. [CrossRef]

49. Caminiti, I.M.; Noci, F.; Muñoz, A.; Whyte, P.; Morgan, D.J.; Cronin, D.A.; Lyng, J.G. Impact of selected combinations of non-thermal processing technologies on the quality of an apple and cranberry juice blend. Food Chem. 2011, 124, 1387-1392 [CrossRef] 
50. Lee, J.; Rennaker, C.; Wrolstad, R.E. Correlation of two anthocyanin quantification methods: HPLC and spectrophotometric methods. Food Chem. 2008, 110, 782-786. [CrossRef]

51. Tonutare, T.; Moor, U.; Szajdak, L. Strawberry anthocyanin determination by ph differential spectroscopic method-How to get true results? Acta Sci. Pol. Hortorum Cultus 2014, 13, 35-47.

52. Li, H.; Deng, Z.; Zhu, H.; Hu, C.; Liu, R.; Young, J.C.; Tsao, R. Highly pigmented vegetables: Anthocyanin compositions and their role in antioxidant activities. Food Res. Int. 2012, 46, 250-259. [CrossRef]

53. Lu, Y.; Pekerti, B.N.; Toh, Z.S.; Broom, F.; Savage, G.; Liu, S.Q.; Huang, D. Physico-chemical parameters and proanthocyanidin profiles of cranberries cultivated in New Zealand. J. Food Compos. Anal. 2017, 63, 1-7. [CrossRef]

54. Grace, M.H.; Massey, A.R.; Mbeunkui, F.; Yousef, G.G.; Lila, M.A. Comparison of health-relevant flavonoids in commonly consumed cranberry products. J. Food Sci. 2012, 77, 176-183. [CrossRef]

55. Lee, S.G.; Vance, T.M.; Nam, T.-G.; Kim, D.-O.; Koo, S.I.; Chun, O.K. Evaluation of pH differential and HPLC methods expressed as cyanidin-3-glucoside equivalent for measuring the total anthocyanin contents of berries. J. Food Meas. Charact. 2016, 10, 562-568. [CrossRef]

56. Diaz-Garcia, L.; Covarrubias-Pazaran, G.; Johnson-Cicalese, J.; Vorsa, N.; Zalapa, J. Genotyping-by-sequencing identifies historical breeding stages of the recently domesticated American cranberry. Front. Plant Sci. 2020, 11, 607770. [CrossRef] [PubMed]

57. Martins, N.; Barros, L.; Ferreira, I.C.F.R. In vivo antioxidant activity of phenolic compounds: Facts and gaps. Trends Food Sci. Technol. 2016, 48, 1-12. [CrossRef]

58. Martín, J.; Kuskoski, E.M.; Navas, M.J.; Asuero, A.G. Antioxidant Capacity of Anthocyanin Pigments. In Flavonoids-From Biosynthesis to Human Health; Justino, C.G., Ed.; Science, Technology and Medicine Open Access: Rijeka, Croatia, 2017; pp. 205-255.

59. Reis, J.F.; Monteiro, V.V.S.; de Souza Gomes, R.; do Carmo, M.M.; da Costa, G.V.; Ribera, P.C.; Monteiro, M.C. Action mechanism and cardiovascular effect of anthocyanins: A systematic review of animal and human studies. J. Transl. Med. 2016, 14, 315. [CrossRef] [PubMed]

60. Chaves, V.C.; Boff, L.; Vizzotto, M.; Calvete, E.; Reginatto, F.H.; Simões, C.M. Berries grown in Brazil: Anthocyanin profiles and biological properties: Chemical composition of berries grown in Brazil. J. Sci. Food Agric. 2018, 98, 4331-4338. [CrossRef]

61. Zeng, Y.; Song, J.; Zhang, M.; Wang, H.; Zhang, Y.; Suo, H. Comparison of in vitro and in vivo antioxidant activities of six flavonoids with similar structures. Antioxidants 2020, 9, 732. [CrossRef]

62. Tian, L.; Tan, Y.; Chen, G.; Wang, G.; Sun, J.; Ou, S.; Chen, W.; Bai, W. Metabolism of anthocyanins and consequent effects on the gut microbiota. Crit. Rev. Food Sci. Nutr. 2019, 59, 982-991. [CrossRef]

63. Milbury, P.E.; Vita, J.A.; Blumberg, J.B. Anthocyanins are bioavailable in humans following an acute dose of cranberry juice. J. Nutr. 2010, 140, 1099-1104. [CrossRef]

64. Lavefve, L.; Howard, L.R.; Carbonero, F. Berry polyphenols metabolism and impact on human gut microbiota and health. Food Funct. 2020, 11, 45-65. [CrossRef]

65. Anhê, F.F.; Roy, D.; Pilon, G.; Dudonné, S.; Matamoros, S.; Varin, T.V.; Garofalo, C.; Moine, Q.; Desjardins, Y.; Levy, E.; et al. A polyphenol-rich cranberry extract protects from diet-induced obesity, insulin resistance and intestinal inflammation in association with increased Akkermansia spp. population in the gut microbiota of mice. Gut 2015, 64, 872-883. [CrossRef] 